\title{
EL PAPEL DE ESPAÑA AL INICIO DE LA GUERRA DE ARGELIA (1954-1956)
}

THE ROLE OF SPAIN AT THE BEGINNING
OF THE ALGERIAN WAR (1954-1956)

Manuel Vidal Muñoz*

Universidad Autónoma de Madrid, España

\begin{abstract}
RESUMEN: España se interesó por la Guerra de Argelia desde su comienzo, el 1 de noviembre de 1954, dada la importante relación histórica, geográfica y cultural entre Argelia y España. Por otra parte el Gobierno franquista, en plenas disputas con Francia por el protectorado marroquí, vio en el conflicto argelino una nueva forma de presionar a la República francesa. El objetivo de este artículo es demostrar que el franquismo tuvo una política argelina además de una política marroquí, si bien es cierto que ambas estaban conectadas y enmarcadas en la política árabe. En las siguientes páginas se analiza el papel que tuvo el franquismo al principio de la Guerra de Argelia con las relaciones franco-españolas y el rol de Estados Unidos como telón de fondo.
\end{abstract}

PALABRAS CLAVE: Guerra de Argelia, España, Francia, Marruecos, Estados Unidos.

ABSTRACT: Spain showed interest in the Algerian War since the beginning of the conflict on November, 1, 1954 because of the historical, geographical and cultural links between Algeria and Spain. On the other hand the Francoist government, in the middle of a struggle against France for the Moroccan protectorate, used the Algerian War as a new way to pressure the French Republic. The goal of this article is to demonstrate that the Francoism had set an Algerian policy apart from a Moroccan policy, even if both were connected in the wider framework of an arab policy. This paper analyzes the involvement of Francoism at the beginning of the Algerian War in the framework of franco-spanish relations and, at the same time, it explains the role of the United States during these first years of the war.

KEYWORDS: Algerian War, Spain, France, Morocco, United States.

* Correspondencia a: Manuel Vidal Muñoz. Rafael Bergamín, 6, Portal 1 Piso 4 Puerta 3, 28043-Madrid (Spain) - manuel.vidalm@predoc.uam.es - https://orcid.org/0000-0003-4611-6263

Cómo citar: Vidal Muñoz, Manuel (2021). «El papel de España al inicio de la guerra de Argelia (1954-1956)»; Historia Contemporánea, 66, 523-556. (https://doi.org/10.1387/hc.21111).

Recibido: 27 septiembre, 2019; aceptado: 20 diciembre, 2019.

ISSN 1130-2402 - eISSN 2340-0277 / (C) 2020 UPV/EHU

(c) (i) $\Theta$ Esta obra está bajo una Licencia

Creative Commons Atribución-NoComercial-SinDerivadas 4.0 Internacional 
Mucho se ha escrito sobre el protectorado español de Marruecos, pero poco se sabe de la estrecha relación mantenida entre España y Argelia tras el fin de la ocupación española de Orán y Mazalquivir en 1792. El final de la colonización española no supuso el término de las relaciones hispano-argelinas, puesto que se mantuvo un intenso intercambio a través de importantes oleadas de inmigrantes españoles a Argelia durante todo el siglo XIX y la primera mitad del siglo $\mathrm{XX}^{1}$, incrementándose el comercio entre ambos territorios, en particular entre los puertos de Alicante y Orán. De hecho en el Oranesado la población europea más importante no era francesa sino española, lo que no hacía sino aumentar el recelo del Gobierno francés hacia su vecino del sur $^{2}$.

Este fuerte vínculo histórico, demográfico, cultural y geográfico fue utilizado por el franquismo como pretexto para apoyar una Argelia independiente, posicionándose en contra de Francia al comienzo de la Guerra de Argelia.

Francia y España estaban enfrentadas desde la creación del protectorado marroquí en 1912 por cuestiones tales como el reparto del territorio jerifiano entre los dos países ${ }^{3}$, la Guerra del $\mathrm{Rif}^{4}$ o la deposición del sultán Mohamed V por parte del Gobierno francés ${ }^{5}$, las cuales habían abierto heridas entre las dos naciones que empujaron al Gobierno español a defender una Argelia independiente. Así pues el Gobierno franquista basó su política argelina en la obra Reivindicaciones de España, publicada en 1941 por los falangistas José María de Areilza y Fernando María Castiella, ambos diplomáticos y ministros de asuntos exteriores durante el franquismo ${ }^{6}$. Los autores de este libro exigían la restitución del Oranesado, territorio argelino que según ellos pertenecía a España por derecho, justificándolo en la ocupación española de Orán y Mazalquivir durante casi trescientos años. Como la anexión del Oranesado era imposible en el contexto internacional posterior a la Segunda Guerra Mundial, el Gobierno español prefirió aumentar su influencia en la región apoyando el independentismo argelino en contra de Francia.

1 Terki Hassaine, 2011. Véase también Zavala, 1885; Bautista Vilar, 1975.

2 Bautista Vilar, 1970. Véase también Latroch, 2012; Ximénez de Sandoval y Madera Vivero, 1853.

3 Delaunay, 2010.

4 Alonso Castrillo, 1958.

5 Dulphy, 2002.

${ }^{6}$ Sobre política exterior franquista: Pereira Castañares (dir.), 2006; Neila Hernández, 2011; López García y Hernando de Larramendi, 2010. 
Ciertamente el Elíseo repudió al régimen de Franco desde su inicio e intentó asfixiarlo con el cierre de la frontera pirenaica de marzo de 1946 a febrero de 1948, en línea con las sanciones que la ONU había impuesto a España el 12 de diciembre de 1946. Para sortear este aislamiento internacional, Franco y su gabinete decidieron enfocar su política exterior hacia el mundo árabe, situándose como un puente entre Occidente y Oriente, lo que, unido a su anticomunismo, permitió la supervivencia del régimen. La política árabe, también llamada de sustitución, obligó al Gobierno francés a revisar el ostracismo al que tenía sometido al franquismo sin que esto supusiese que aceptase la dictadura española.

Muestra de ello fue la protección que las autoridades francesas confirieron a los exiliados republicanos huidos del franquismo tras la Guerra Civil, quienes organizaron un verdadero núcleo de resistencia en el Hexágono. Este contencioso bilateral fue utilizado por ambas administraciones como moneda de cambio en el norte de África durante el protectorado marroquí y, posteriormente, en la Guerra de Argelia. Es decir que cuando España disminuía su amparo a los nacionalistas magrebíes, Francia le respondía retirando su ayuda a los republicanos españoles y viceversa ${ }^{7}$.

Éste era el contexto franco-español al comienzo de la Guerra de Argelia ${ }^{8}$ mas, si bien todo esto era cierto, también lo era que Argelia representaba para Francia algo mucho más importante que Marruecos o Túnez. Argelia era un departamento que formaba parte del territorio francés mientras que sus dos vecinos eran protectorados, por lo que las injerencias extranjeras no fueron aceptadas por el Gobierno francés.

\section{Estado de la cuestión}

Aún así las hubo, como demuestran los estudios sobre las posturas mantenidas por Estados Unidos, la Unión Soviética, Suiza, Reino Unido y Alemania en la Guerra de Argelia ${ }^{9}$ ¿ ¿Y España? ¿Existen escritos sobre su participación en este episodio histórico? Lo cierto es que sí pero muy pocos. Las publicaciones existentes sobre las relaciones hispano-argelinas suelen estar enfocadas a épocas anteriores a la guerra, principalmente a la

\footnotetext{
7 Malgat, 1997, p. 19.

8 Sobre la Guerra de Argelia véase: Thénault, 2012; De Rochebrune y Stora, 2011; Pervillé, 2008.

9 Branche, 2005.
} 
etapa de la colonización española de Orán y Mazalquivir. A continuación voy a exponer las más significativas.

Jean-Marc Delaunay, historiador francés y profesor emérito de la Universidad Sorbonne Nouvelle - Paris 3, redactó una tesis doctoral titulada, Méfiance cordiale. Les relations franco-espagnoles de la fin du XIXème siècle à la Première Guerre Mondiale, publicada en 2011. En ella el autor analiza las relaciones franco-españolas de finales del siglo XIX hasta la Primera Guerra Mundial. Los tres tomos que forman esta tesis son únicos por su nivel de detalle y por examinar las relaciones bilaterales durante la Belle Époque. En el segundo volumen, Les relations coloniales, el autor explica los primeros contenciosos hispano-franceses en África del Norte, entre los que se encuentra Argelia.

Por otro lado la historiadora francesa Anne Dulphy escribió un artículo de trece páginas titulado, «La Guerre d'Algérie dans les relations franco-espagnoles. Enjeux spécifiques et éléments de comparaison avec l'Italie », publicado en la revista Cahiers de la Méditerranée en 2005. La autora explica de forma muy resumida el papel que jugó España en la guerra y lo compara con el de Italia.

Además de este artículo, recientemente ha publicado un libro titulado L'Algérie des pieds-noirs: Entre l'Espagne et la France, Vendémiaire, 2014 que trata principalmente de la inmigración española en Argelia y viceversa.

Por lo que se refiere a historiadores españoles, se ha estudiado muy extensamente el protectorado marroquí quedando en un segundo plano la relación entre España y Argelia.

La presencia española en este país ha sido analizada por Gregorio Sánchez Doncel en su libro, Presencia de España en Orán (1509-1792), publicado en 1991 por el Estudio Teológico de San Ildefonso.

El historiador de la Universidad de Murcia, Juan Bautista Vilar, ha investigado sobre la inmigración española en Argelia así como sobre la prensa española en dicho país, particularmente activa en los años treinta.

La profesora titular del departamento de historia contemporánea de la UNED, María Concepción Ybarra Enríquez de la Orden, escribió un ensayo titulado España y la descolonización del Magreb: Rivalidad hispano-francesa en Marruecos 1951-1961. La autora examina primordialmente las relaciones bilaterales con respecto al Marruecos español pero destina el capítulo XV a la cuestión argelina.

María Dolores Algora Weber, profesora de relaciones internacionales y historia contemporánea en la Universidad CEU San Pablo, ha investigado las ambiguiedades del franquismo hacia los países árabes, concre- 
tamente hacia Argelia en el capítulo: «Argelia en la política exterior del régimen de Franco: continuidad o ruptura en la tradicional amistad hispano-árabe». En: Del aislamiento a la apertura: la política exterior de España durante el franquismo, Comisión Española de Historia de las Relaciones Internacionales, Madrid, 2006.

El catedrático de seguridad y cooperación en las relaciones internacionales de la Universidad Complutense de Madrid, Antonio Marquina Barrio, dirigió una obra colectiva titulada Las relaciones hispano-argelinas publicada en 2012. El libro está dividido en dos partes, la primera trata sobre las relaciones históricas y políticas entre España y Argelia del siglo XIX hasta la actualidad. La segunda parte está dedicada a las relaciones económicas entre los dos países. En concreto el capítulo 2 evoca el tema de este artículo, «España-Argelia durante el franquismo. Difíciles relaciones de dos países inacabados»; escrito por Domingo del Pino, periodista especializado en el Magreb. El capítulo no tiene más de diez páginas por lo que el autor ofrece una explicación demasiado superficial sobre un tema mucho más complejo.

Otra obra colectiva sobre las relaciones hispano-argelinas es Las campanas de Orán, 1509-2009, publicada en 2012 por la Universidad de Alcalá de Henares. Es un libro escrito por historiadores españoles, turcos y argelinos en el que se hace un recorrido histórico de Argelia y España de 1509 a 2009; aunque ni siquiera se menciona la participación española en la Guerra de Argelia. Los editores son el historiador argelino de la Universidad de Orán Ismet Terki-Hassaine, el historiador español Emilio Sola, el profesor de historia contemporánea de la Universidad de Alcalá Alejandro R. Díez Torre y el también profesor de la Universidad de Alcalá Manuel Casado Arboniés.

Más reciente es el libro editado por los historiadores de la Universidad Pompeu Fabra, Eloy Martín Corrales y Josep Pich Mitjana, La guerra de independencia de Argelia y sus repercusiones en España, publicado en 2018 por Bellaterra. Este escrito realizado por investigadores españoles y franceses trata sobre ciertos aspectos concretos de la guerra argelina y su conexión con España. Desde los más clásicos como la $\mathrm{OAS}^{10} \mathrm{o}$ los piedsnoirs, hasta temas menos estudiados como la relación del socialismo español con la Guerra de Argelia.

Por último el escrito que más se acerca a mi investigación es la tesina de DEA (antiguo Máster 2 francés), «L'Algérie dans les relations francoespagnoles, 1954-1964 » de Maruja Otero, ex estudiante de Sciences Po

10 Torres García, 2018. 
que defendió su tesina en 1996. La autora dispuso de fuentes fiables, sobre todo en lo que concierne al apoyo diplomático español a la independencia argelina. Sin embargo Maruja Otero carecía de informaciones sobre el apoyo logístico español a los rebeldes argelinos.

Este resumen historiográfico de España y la Guerra de Argelia da una idea de la gran cantidad de enfoques desde los cuales los investigadores han estudiado el tema. No obstante no se ha profundizado lo suficiente en el apoyo logístico español a los muyahidines argelinos, decisivo durante estos primeros años de la guerra, laguna que trataré de subsanar con este artículo. Para ello he investigado en archivos del Ministerio de la Presidencia del Gobierno, del AGA, del Ministerio de Asuntos Exteriores francés, del Servicio Histórico de Defensa francés y del FRUS; así como he entrevistado a un familiar de un importante traficante de armas.

\section{La Toussaint rouge}

La Guerra de Argelia comenzó el 1 de noviembre de 1954, la Toussaint rouge, con una serie de atentados en Argelia contra el ejército francés, instalaciones militares, comisarías, almacenes, centros de comunicaciones y edificios públicos. Dichos actos fueron perpetrados por el Frente de Liberación Nacional (FLN); creado en marzo de 195411, fue el movimiento que se impuso como el representante principal del independentismo argelino. Sus líderes proclamaban la lucha armada contra Francia para alcanzar la emancipación de Argelia.

El Gobierno español no fue indiferente a lo que ocurría, ya que estaba en plenas disputas con Francia por el protectorado marroquí. Los revolucionarios argelinos representaban para Franco una nueva oportunidad de presionar a los franceses en pos de mayor legitimidad internacional.

Por consiguiente la prensa española, controlada por el régimen, no tardó en posicionarse a favor de los independentistas argelinos. El periódico católico $Y a$ comparó la acción militar francesa en Argelia a una guerra de exterminio, y Radio Tetuán exaltó la resistencia del Ejército de Liberación Nacional (ALN) tras los atentados del 1 de noviembre de $1954^{12}$.

11 Algora Weber, 2006, p. 255.

12 AMAE, Télégramme du résident général à Rabat, Lacoste à Marotini à Paris, 13 de noviembre de 1954 (París, del 6 de noviembre de 1951 al 31 de marzo de 1955), serie Europa 1949-1955, subserie España, dossier 116. 
Otros medios de comunicación españoles fueron más lejos y comenzaron a propagar la idea de que no existía separación alguna - ya fuese geográfica, cultural o política- entre el norte de África y la península ibérica. Un artículo del diario El Alcázar resumía muy bien esta imagen:

«La geografía nos indica que África del Norte y la península ibérica conforman un mundo aparte, dotado de una personalidad evidente: un mundo importante y crucial. Nace en Europa, parece querer ser África y muere en el desierto del Sahara [...] Constituye un conjunto geográfico sobre el cual la historia ha tendido una trama de penetraciones constantes entre sus dos orillas.» ${ }^{13}$

El 2 de noviembre de 1954 un artículo del Sr. Mostaza en el periódico $Y a$ recordaba que en Argelia vivían 100.000 ciudadanos españoles y 700.000 españoles nacionalizados franceses, sin contar los descendientes de siglos pasados que ya habían sido absorbidos por Francia ${ }^{14}$. Una de las últimas publicaciones de 1954 sobre la cuestión argelina fue la del 10 de diciembre en el periódico $Y a$, escrita por el Sr. Gómez Salomé. Éste afirmaba que la población argelina, en crecimiento constante, se había visto obligada a la rebelión por la política de acaparamiento de tierras e industrias por parte de los colonos franceses ${ }^{15}$.

Esta postura pro Argelia independiente de la prensa española se reflejó en los altos mandos franquistas. La fuerte vinculación al norte de África de los militares de la generación del 15, los llamados «africanistas», se debía a que la mayor parte de su trayectoria profesional transcurrió en Marruecos. Los africanistas monopolizaban la política magrebí desde la dictadura de Primo de Rivera, el cual asoció los temas africanos a Presidencia del Gobierno dirigida por el almirante Carrero Blanco, de ahí que su rol en esta área fuese determinante frente al de los diplomáticos, al menos al principio de la Guerra de Argelia ${ }^{16}$.

13 Dulphy, 2018, p. 17.

14 AMAE, Télégramme signé par Meyrier au Quai d'Orsay, 5 de noviembre de 1954 (París, del 6 de noviembre de 1951 al 31 de marzo de 1955), serie Europa 1949-1955, subserie España, dossier 116.

15 AMAE (París, del 6 de noviembre de 1951 al 31 de marzo de 1955), serie Europa 1949-1955, subserie España, dossier 116.

${ }^{16}$ Sobre el africanismo: Morales Lezcano, 1989; Balfour, 2000 e Iglesias Amorín, 2016. En cuanto a la organización administrativa del protectorado véase: Villanova, 2004. 
Entre ellos destacó el más firme defensor de la política proárabe ${ }^{17}$, Rafael García Valiño, el Alto Comisario de España en Marruecos quién el 1 de noviembre de 1954 envió un comunicado a Presidencia del Gobierno que decía lo siguiente: «El levantamiento de Argelia ha producido gran impresión y alegría entre los rifeños, así como en general, en nuestra zona.» ${ }^{18}$ Luego añadió que en Chauen (zona jalifiana) se habían reunido familias para hacer oración por el triunfo de los rebeldes; lo que demuestra la fuerte unión existente en la época entre marroquíes y argelinos. Tanto era así que los marroquíes que leían El Telegrama del Rif y escuchaban Radio Nacional se habían sorprendido por el calificativo de terroristas que la Agencia EFE aplicaba a los combatientes de Argelia. Se entiende de esto último que el Alto Comisario pedía a la administración peninsular que evitase en la prensa cualquier denostación hacia los revolucionarios argelinos.

Asimismo García Valiño explicaba que como consecuencia de la situación en Argelia, la policía francesa hacía detenciones injustas entre los braceros de la zona española, a los que expulsaban del Marruecos francés como sospechosos. Por otro lado García Valiño informaba de que la rebelión en Argelia había aumentado la preocupación y la inquietud en zona francesa, dónde la mayoría de los colonos franceses se marchaba por la noche a las ciudades y regresaban a sus fincas por la mañana temprano ante el temor de agresiones o de que les exigieran dinero.

La noticia de un segundo frente en Argelia (además del de Marruecos) era muy positiva para el general Valiño que quería debilitar a Francia en el norte de África. Dicho de otra manera, el Alto Comisario compartía el júbilo de la mayoría de los rifeños después de los atentados de Argelia.

Más concretamente, el apoyo español se traducía en el suministro de armas a los rebeldes argelinos a través de la frontera entre Marruecos y Argelia. Este tráfico de armas beneficiaba a las tribus bereberes, que cometían sabotajes en el Marruecos francés y en el oeste de Argelia. Igualmente, desde noviembre de 1954 los servicios secretos españoles favorecían la creación de las primeras unidades de la ALN en Tánger ${ }^{19}$. No contentos con eso los franquistas ofrecían la antena de Radio Tetuán para

17 Hernando de Larramendi, 2017.

18 ACMP, Resumen de información (Madrid, del 1 al 13 de noviembre de 1954), Serie J.E., Alta Comisaría de España en Marruecos, Gabinete Diplomático, expediente 21.

19 González Mata, 1977, p. 22. Sobre el origen de los servicios secretos españoles véase: Paniagua López, 2018. 
que se emitiese desde El Cairo el programa antifrancés, La Voix des Arabes, en el que se podía escuchar el 3 de noviembre:

«El corazón de cada argelino rebosa de odio hacia los franceses que le han quitado su libertad y mancillado su honor. Todo argelino está dispuesto a sacrificar su sangre y su vida para elevar el estandarte de su país sobre el cuerpo de los franceses...» ${ }^{20}$

Ante la ayuda incondicional de los españoles a los nacionalistas magrebíes, el ejército francés respondía sobornando a soldados españoles llamándoles a desertar a cambio de la libertad y de un nuevo estado civil, así como intentaba bloquear la señal de Radio Tetuán ${ }^{21}$.

Pero para que el franquismo pudiese actuar con semejante atrevimiento contra Francia, había sido necesario el respaldo al régimen de la superpotencia estadounidense. Estados Unidos fue el principal valedor del franquismo en la escena internacional por el carácter anticomunista de la dictadura española. El Gobierno de Harry Truman primero y el de Eisenhower después vieron a Franco como un aliado en la Guerra Fría, culminando su asociación con la firma de los Pactos de Madrid en 1953. Dicho acuerdo estableció la instalación de cuatro bases militares norteamericanas en suelo español a cambio de ayuda económica y militar, y supuso un espaldarazo definitivo a Francisco Franco ${ }^{22}$.

En cuanto a la Guerra de Argelia el liderazgo de Occidente por parte de Estados Unidos tras la Segunda Guerra Mundial era tal que se implicó en mayor o menor grado en todos los conflictos de la segunda mitad del siglo XX, dado que todas las contiendas que comenzaron tras la Segunda Guerra Mundial estaban conectadas con la Guerra Fría entre Estados Unidos y la URSS. De hecho la principal preocupación del presidente de Estados Unidos entre 1951 y 1963, Dwight Eisenhower, era que África del Norte no cayese bajo influencia comunista.

Parece que esta premisa se cumplía al principio de la guerra ya que, según el historiador norteamericano Irwin Wall, el Bloque del Este no influenció a los rebeldes argelinos. Esta coyuntura permitió a Estados Unidos volver a su postura anticolonialista, abandonada durante la Guerra de

\footnotetext{
20 (traducido del francés) Michal, 2012.

21 González Mata, 1977, p. 24.

22 Sobre las relaciones entre la España franquista y los Estados Unidos: Delgado Gómez-Escalonilla, 2003.
} 
Indochina por el apoyo comunista al Viet Minh, y mostrarse conciliadores con la revolución argelina.

Argelia era para Estados Unidos un ejemplo de lo que debía ser la revolución del tercer mundo, pues ésta parecía capaz de instaurar un régimen democrático y no comunista. Por su lado los muyahidines eran muy conscientes de que tenían que evitar elegir uno de los dos bloques de la Guerra Fría.

Sin embargo el Gobierno estadounidense no podía estar totalmente opuesto a su tradicional aliado, Francia, que además estaba llamada a ser el puntal de la defensa europea en el marco de la OTAN. En consecuencia el Departamento de Estado se puso un objetivo casi imposible: mantener un diálogo constructivo durante la contienda con las dos partes comprometidas, el Gobierno francés y el FLN.

Naturalmente este equilibrio era inalcanzable y la balanza se inclinó hacia el lado argelino.

Esto se debió principalmente al convencimiento de las autoridades norteamericanas de que el bloque comunista no influenciaba al FLN, como muy bien apuntaba el Secretario de Estado, John Foster Dulles, en marzo de 1958. Ante el National Security Council afirmó que frente a las tres crisis más preocupantes del momento - Indonesia, África del Norte y Oriente Medio- el comunismo y la URSS estaban ausentes, que no se percibía huella alguna de complots soviéticos y que en cambio la amenaza inmediata parecía tener su origen en el fundamentalismo islámico ${ }^{23}$.

El reducido papel del marxismo se unió a la torpe actuación de la IV República francesa, que retiró sus tropas de la OTAN en Alemania para trasladarlas a Argelia, convenciendo así a Estados Unidos de ponerse del lado argelino ${ }^{24}$.

Así pues, la Guerra de Argelia dañó considerablemente las relaciones franco-estadounidenses, a pesar de que el Gobierno norteamericano intentase suavizar los desencuentros entre las dos administraciones.

No obstante, Estados Unidos no fue el único país en posicionarse con respecto a la Guerra de Argelia, cuya dimensión internacional no ha pasado desapercibida para Irwin Wall, que dedica un pequeño apartado a la actitud de otros países frente a la Guerra de Argelia; eso sí sin ni siquiera mencionar a España.

23 Wall, 2006, p. 37.

24 Connelly, 2002, p. 165. 


\section{EI RIF: Retaguardia de la revolución argelina}

¿Y España? ¿Tuvo algún papel en el frenético pulso entre Francia y Estados Unidos por Argelia?

Lo cierto es que sí pero pequeño, conforme al tamaño que ocupaba España en la escena internacional como potencia de segundo orden.

La rivalidad de Estados Unidos con los soviéticos era lo más importante para el general Eisenhower, que quería que la guerra en Argelia terminase pronto a fin de evitar una penetración rusa en África del Norte. Para ello no dejó de insistir al Gobierno francés que negociase con los rebeldes argelinos $\mathrm{y}$, precisamente para facilitar estas conversaciones, el Gobierno estadounidense intentaba presionar al franquismo con el objetivo de que suspendiese la campaña mediática proárabe. No debió de intimidar mucho a los franquistas que no retiraron los mensajes pro Argelia independiente. De hecho tampoco funcionó con otros líderes árabes, como los egipcios, que no abandonaron a los felagas argelinos ${ }^{25}$. Con estas acciones el gabinete de Eisenhower intentaba en vano demostrar a los franceses su buena voluntad.

A Franco le preocupaba perder el norte de África, como dejó patente en una carta enviada al presidente Eisenhower el 6 de abril de 1956. En la misma consideraba que el problema de África del Norte concernía a todo Occidente y, afirmaba que era necesario ser leales hacia los pueblos norteafricanos para no perder su confianza. Había que ayudarlos a resolver sus problemas, permitirles cumplir sus sueños y mejorar su calidad de vida por sí mismos, pues ésta sería la mejor vía para garantizar el orden y la seguridad con la que todos saldrían ganando. Más adelante en su carta el caudillo criticaba a la nación francesa por su atrasada mentalidad propia del siglo XIX y a raíz de esto se refería a la Guerra de Argelia, la cual había tomado un cariz negro que impedía encontrar una solución adecuada. Por último añadía que si Francia conseguía ahogar momentáneamente la rebelión, su intención sería intentar tomar ventaja de esa pírrica victoria, olvidando que la represión violenta no eliminaría el espíritu de independencia una vez que éste había echado raíces en un pueblo que además, en este caso, contaba con el apoyo y simpatía de sus vecinos ${ }^{26}$.

25 FRUS, Progress report on NSC 5436/1. United States policy on French North Africa (Tunisia, Morocco, Algeria), (Washington, June 1, 1955), 1955-1957, Africa, Volume XVIII. 25. Operations coordinating board report.

${ }_{26}$ FRUS, Letter from General Franco to President Eisenhower (Madrid, April 6, 1956), 1955-1957, Western Europe and Canada, Volume XXVII, 196. 
Lo que resulta determinante en esta carta es que Franco no escondía su complicidad con la revolución magrebí y su aversión hacia Francia. No está claro lo que sabía exactamente el Gobierno de Estados Unidos sobre las acciones españolas a favor de la rebelión argelina, pero es probable que conociese la implicación del franquismo en la contienda sin saber su grado exacto de participación. Así lo resumió Julius Holmes - American Minister to Tangier - quién no creía, al contrario que los franceses, que los ataques en la zona francesa de Marruecos fueran organizados en la zona española, aunque sí consideraba probable que los individuos que se fugaban a la zona española formasen parte de los ataques ${ }^{27}$. Esta fórmula ambigua y la carta de Franco a Eisenhower dejan entrever un conocimiento, por parte de los representantes estadounidenses, de la intervención española en las revoluciones magrebíes. En cualquier caso, Estados Unidos no opuso una resistencia real a la política proárabe de Franco con la que, en el fondo, estaba de acuerdo ${ }^{28}$.

Es más, el apoyo español a la revolución argelina se intensificó con la llegada del año 1955. Una vez más la prensa era la cara más visible del patrocinio franquista a la causa argelina. El 16 de enero de 1955 se podía leer en un artículo del Sr. Lucientes en el periódico Arriba que desde noviembre en Argelia reinaba un doble régimen de terrorismo y contraterrorismo, poniendo al mismo nivel a los combatientes argelinos y al ejército francés ${ }^{29}$. Para acompañar a la prensa peninsular apareció en el protectorado un nuevo periódico, Aquí Marruecos, y ya en su primera tirada se publicaron escritos favorables a la revolución argelina como por ejemplo: «Por el mito de la nacionalidad francesa Francia atrae a su territorio a los argelinos donde son el objeto de una explotación y una discriminación odiosas.» ${ }^{30}$ Poco después, los días 18 y 19 de marzo de 1955, en Radio Madrid se escucharon las siguientes noticias:

«En Argelia los redentores han incendiado la granja de un colono francés situada en la cordillera del Orés. Varios tractores y camiones

${ }^{27}$ FRUS, Memorandum of a conversation, Department of State (Washington, October 3, 1955), 1955-1957, Africa, Volume XVIII. 184.

${ }_{28}$ Connelly, 2002, p. 61.

${ }^{29}$ AMAE (París, del 6 de noviembre de 1951 al 31 de marzo de 1955), serie Europa 1949-1955, subserie España, dossier 116.

30 AMAE, Guy de la Tournelle au Ministre des Affaires Étrangères, 21 de febrero de 1955 (París, del 6 de noviembre de 1951 al 31 de marzo de 1955), serie Europa 1949-1955, subserie España, dossier 116. 
han sido quemados. Los redentores no se detuvieron ahí; dispararon a los obreros de la granja de los cuales secuestraron a dos.»31

Naturalmente el Gobierno francés había comprendido que la zona española de Marruecos ya no era sólo una base para los nacionalistas marroquíes, sino también para los nacionalistas argelinos. Durante todo el año 1955 hubo una serie de denuncias por parte de la administración francesa con respecto al tráfico de armas en la frontera argelina-marroquí. El Mando superior francés de las tropas de Marruecos confirmó que Melilla se había convertido en un punto de llegada y almacenamiento de armas y de material. Por ejemplo las tropas españolas de Marruecos estaban dotadas de granadas «BREDA », las mismas utilizadas por los terroristas de la zona francesa ${ }^{32}$. Los rebeldes magrebíes estaban presentes por toda la frontera española de Marruecos: frente a Mezguitem, Tizi Ouasli, Jebel Bou Zineb y sin duda, aunque todavía no se habían manifestado, al oeste en Uezán. En la retaguardia de los grupos rebeldes había un puesto de mando que dirigía un taller de reparación y de fabricación de bombas y granadas. Ya desde antes del 1 de octubre de 1955 - día en que fueron atacados los puestos fronterizos de la región de Boured Aknoul- fueron colocados varios depósitos de armas cerca de la frontera entre los dos Marruecos. Asimismo, antes de que estallasen combates en el norte del Imperio Jerifiano, los nacionalistas marroquíes de la zona española reclutaban entre los refugiados argelinos a los futuros soldados formados en los centros de instrucción de Melilla, Tetuán y Nador. Por su lado, los rebeldes argelinos reclutaban abiertamente y sin dificultades voluntarios en el Marruecos español para la guerra en Argelia. Desde hacía varios meses funcionaban circuitos por los que a través de Tetuán, Alcazarquivir y Tánger eran enviados a Europa y Oriente Medio los jefes nacionalistas y comandos, cuyo destino final era Egipto dónde recibían instrucción militar ${ }^{33}$.

Los líderes norteafricanos se desplazaban fácilmente en el norte de Marruecos ya que estaban protegidos por el Alto Comisario Rafael García

31 AMAE, Télégramme de Lacoste au Quai d'Orsay (París, del 6 de noviembre de 1951 al 31 de marzo de 1955), serie Europa 1949-1955, subserie España, dossier 116.

32 SHD, SHAT, Bulletin Trimestriel de renseignements sur le Maroc espagnol (del 1 de abril al 30 de junio de 1955), Commandement Supérieur des troupes du Maroc, Dossier GR 10 T 311.

33 SHD, SHAT, Fiche à l'attention du Général d'Armée (12 de diciembre de 1955), Commandement Supérieur des troupes du Maroc, Dossier GR 10 T 311. 
Valiño, quién ordenaba a los funcionarios españoles entregarles pasaportes y salvoconductos. En muchas ocasiones el destino final de sus viajes era Madrid, que se convirtió en un centro neurálgico para los nacionalistas magrebíes. Así pues los principales rostros de la revolución argelina, el líder Ahmed Ben Bella, Husein Aït Ahmed, Mohamed Khider entre otros organizaban reuniones en la capital española. También era el caso del dirigente del partido Istiqlal marroquí Allal El Fassi que citaba a sus partisanos en los apartamentos « liberados » de Madrid, dónde se elaboraban discursos y proyectos independentistas que luego eran difundidos en numerosas radios españolas.

Incluso antes de la guerra, en junio de 1954, dirigentes del FLN y del Istiqlal se reunieron en Madrid. Cuando terminó el encuentro, El Fassi declaró al corresponsal de Agence France Presse en la capital española que:

«Tenemos con España lazos de sangre. Nuestros intereses son paralelos. Si el pueblo marroquí ha aportado una ayuda leal y eficaz a España durante su guerra [la Guerra Civil], por su parte España se ha colocado deliberadamente del lado de Marruecos en su lucha por la independencia y por el regreso de Mohamed V. Los marroquíes lo reconocen y lo proclaman.» ${ }^{34}$

Sin duda Franco estaba al corriente de todas estas actividades que no frenaba para mantener su amistad con los países árabes (nota 36). De esta forma quería evitar que los nacionalistas marroquíes se opusieran a la colonización española de Marruecos, aunque fue inútil como ya sabemos.

Del lado francés el Gobierno multiplicaba sus quejas y denuncias contra España y tras el ataque en la región de Boured Aknoul en octubre de 1955, el embajador de Francia en el Reino Unido, Jean Chauvel, le envío a su homólogo en España, Guy Le Roy de la Tournelle, un comunicado sobre el contrabando de armas en África del Norte. Según este documento un corresponsal del periódico británico Daily Mail, Noel Barber, había descubierto el camino por donde se pasaban las armas a los rebeldes del Rif a través del Marruecos español. También denunciaba un hospital en Nador donde se curaba a los magrebíes heridos ${ }^{35}$; aunque el de Nador no era el único hospital puesto a disposición de los muyahidines. Por citar un ejemplo representativo, el líder nacionalista Mohamed Boudiaf fue ope-

\footnotetext{
34 (traducido del francés) Santamaría, 1984, p. 18.

35 Ybarra Enríquez de la Orden, 1998, Cap. XV.
} 
rado del pulmón con éxito en el hospital Benkérich de Tetuán. Por otra parte había una enfermería en la pequeña localidad de Ain Zohra.

Es preciso detenerse en el recorrido del jefe argelino Boudiaf, el cual tuvo un papel fundamental en la conexión entre la zona española de Marruecos y Argelia puesto que, desde el principio de la guerra, se instaló en Tetuán y Nador desde dónde estableció fuertes vínculos con la resistencia marroquí. Uno de los principales jefes nacionalistas marroquíes implicado con Boudiaf fue el Doctor Abdelkrim al-Khatib, al servicio de l'Armée de Libération Marocaine (ALM), que facilitó la convergencia entre los puntos de vista españoles, marroquíes y argelinos para que Nador se convirtiese en un centro de la resistencia marroquí y argelina. Esto se hizo en el más absoluto secreto, con el consentimiento del general Franco ${ }^{36}$.

A Boudiaf se unieron, a partir de marzo de 1955, varios responsables del FLN y de la Wilaya $V^{37}$ en el hotel Abdelkader Bouanan de Nador, dónde eran protegidos por el ejército de liberación de Marruecos y por las autoridades coloniales españolas. Allí recibieron armamento egipcio de los barcos «Dina» y «Farouk» y, durante el verano de 1956, se transfirieron 500 armas al mes desde Tánger hacia Nador, Oujda y Figuig (frontera argelina-marroquí). El destino de las armas era la Wilaya V, la más grande y la correspondiente al Oranesado, que se beneficiaba del armamento de la ALM.

Así fue como Boudiaf instauró una sólida red de contrabando entre el Marruecos español y el oeste de Argelia ${ }^{38}$. Esta unión de soldados marroquíes y argelinos se confirmó con el ya varias veces mencionado ataque en Boured Aknoul, del 1 y 2 de octubre de 1955, pues fue coordinado con una oleada de atentados terroristas en el Oranesado.

En el terreno político, la ligazón magrebí se materializó en los acuerdos alcanzados en El Cairo por Allal El Fassi, el líder rifeño Abdelkrim y Ben Bella reunidos para formar un ejército de liberación con un mando unificado que dirigiera la lucha en Argelia y Marruecos. Esta solidaridad magrebí se extendió al ámbito internacional a través de la creación del Bloque de Bandung ${ }^{39}$ que institucionalizó al Tercer Mundo. Su voz

36 Guentari, 2002, p. 56.

37 O valiato: subdivisión administrativa de algunos países musulmanes. En este caso la Wilaya es una provincia argelina. La Wilaya V estaba comandada por Larbi Ben M'hidi, en contacto permanente con Mohamed Boudiaf.

38 Benbelaïd, 2007, pp. 31-36.

39 Creado en la Conferencia de Bandung del 18 al 24 de abril de 1955. 
comenzó a oírse con fuerza a partir de septiembre de 1955, cuando los miembros del bloque tercermundista decidieron abandonar la política de espera seguida hasta ese momento, para reemplazarla por ofensivas diplomáticas en la ONU que constituían una fuerte amenaza para Francia.

Desde París, el gabinete de Edgar Faure no quería saber nada de las reivindicaciones del Bloque de Bandung, $\mathrm{y}$ ansiaba recuperar a toda costa el control de Argelia.

Las numerosas pruebas del apoyo español a la rebelión argelina-marroquí enfurecían cada vez más al embajador francés en España, De la Tournelle, que acusó al jefe del partido nacionalista rifeño y protegido de García Valiño, Abdelkhalek Torres, de estar implicado en el contrabando de armas. Para intentar calmar los ánimos, el embajador español en Francia, el conde de Casa Rojas, desmentía constantemente ante la prensa francesa las acusaciones contra España. No sirvió de nada y, a finales del año 1955, la prensa francesa emprendió una campaña mediática contra España en la que los periodistas acusaban al Alto Comisario de proteger extremistas magrebíes que atentaban contra Francia. Con el propósito de demostrar su inocencia, García Valiño invitó al Residente General francés en Marruecos a enviar un jefe militar al Rif para comprobar los puestos fronterizos. Asimismo, el Ministro de exteriores Martín Artajo simuló estar ofendido, amenazando al Gobierno francés con denunciarlo a las Naciones Unidas si proseguían las acusaciones contra España ${ }^{40}$.

Con certeza la entrada de España en la ONU el 14 de diciembre de 1955 confortó al franquismo, y le dio alas en el plano internacional para reforzar su política «anticolonialista», presentándose como el liberador de los pueblos oprimidos ${ }^{41}$. Desde el comienzo de la Guerra de Argelia las autoridades coloniales españolas apoyaron activamente a los combatientes argelinos, aunque lo desmintieran constantemente a través de canales oficiales. La diplomacia de la inestable IV República francesa era incapaz de frenar el ímpetu franquista, que utilizaba todas las artimañas posibles para ejercer su influencia en el Magreb. Francia votó a favor del ingreso de España en la ONU con la esperanza de disuadir al franquismo de seguir con su política argelina ${ }^{42}$. Pero ni así pudo evitar que el protectorado español

40 Ybarra Enríquez de la Orden, 1998, Cap. XV.

${ }^{41}$ El resultado de la votación sobre la entrada de España en la ONU en el Consejo de Seguridad fue de ocho votos contra ninguno y tres abstenciones (Bélgica, China y Estados Unidos). Sobre la abstención de Estados Unidos consultar: Lleonart Anselem, 1995.

42 Dulphy, 2002, p. 720. 
se convirtiese en una auténtica base de operaciones para los felagas y, durante el año 1956, la ayuda española a los argelinos se extendió y ramificó; aunque también llegó a sus límites. Unos límites marcados por la independencia de Marruecos que, lentamente, transformó la relación entre España y Argelia.

\section{España: ¿vanguardia de la revolución argelina?}

El año 1956 comenzó igual que había terminado 1955, es decir que el franquismo continuó apoyando al FLN con la misma intensidad.

Justo antes de la independencia del Protectorado de Marruecos, el Gobierno franquista decidió dar un paso más en su apoyo a la rebelión argelina convirtiéndolo en prácticamente oficial. Así fue como el 5 de abril de 1956 Franco declaró sobre la Guerra de Argelia que:

«El Imperio marroquí habiendo recobrado el derecho a decidir su porvenir, es posible vislumbrar un mañana en el que la emancipación de otros pueblos mediterráneos y su evolución económica y cultural permitan a las naciones ribereñas de nuestro mar latino defender y salvaguardar, por sí mismas, en paz y harmonía, el orden y la libertad de sus relaciones.» ${ }^{43}$

Como se puede observar, Franco no citaba directamente Argelia para así poder cambiar fácilmente de discurso si el Gobierno francés le acusaba de apoyar al FLN. Por lo tanto la independencia de Marruecos no frenó, al menos en un primer momento, la política proárabe de Franco. Pero más concretamente ¿Por qué se empeñaba el franquismo en apoyar una Argelia independiente tras la pérdida del protectorado? En este nuevo escenario, Argelia representaba otro frente norteafricano para el ejército espanool, históricamente ligado a esta tierra y terriblemente decepcionado por el fin de la presencia española en el norte de Marruecos. Además, las responsables de la ayuda logística a la revolución argelina eran las tropas españolas, las cuales permanecieron en la zona norte de Marruecos hasta su retirada definitiva el 31 de agosto de 1961, mucho después de la independencia del Imperio Jerifiano el 7 abril de 1956.

43 Otero, 1996, I-2. 
Por otra parte, el hecho de no poseer territorio en Argelia legitimaba la versión oficial franquista, según la cual el Gobierno español ayudaba desinteresadamente a los pueblos árabes a conquistar su independencia. Por último, la implicación española en Argelia permitía al franquismo mantener la presión sobre el Gobierno francés, que seguía auxiliando al republicanismo español en Francia.

En otro orden de cosas Franco había comprendido que no podía conservar el protectorado marroquí por la concesión francesa de independencia a Marruecos y por la presión del sultán Mohamed V, pero que era posible mantener en África una posición internacional interesante para España a través de otros mecanismos. En consecuencia la política árabe evolucionó dado que su primer objetivo, sortear el aislamiento internacional, se había cumplido gracias a los Pactos de Madrid de 1953 con Estados Unidos y a la entrada de España en la ONU en 1955. Su nueva meta sería convertir a España en el centro del Mediterráneo mediante la construcción de una organización mediterránea en la que España representase al conjunto atlántico y, consecuentemente, era indispensable la paz e independencia de Argelia. Por este motivo Martín Artajo dijo el 10 de abril de 1956, justo antes de visitar los Estados Unidos, que:

«[...] consecuencia natural de la posición geográfica de España, este pacto requiere la resolución de los problemas de Oriente Medio y del norte de África para que los países ribereños puedan, en pie de igualdad, participar en la defensa.» ${ }^{44}$

Estas palabras del jefe de la diplomacia española esclarecían las intenciones franquistas. El Gobierno español quería recuperar el proyecto del Pacto Mediterráneo para integrarse en un acuerdo militar alternativo a la OTAN, en la que España no había sido aceptada, con una posible presencia de Estados Unidos en el mismo.

En este sentido el franquismo intensificó la campaña antifrancesa, autoridades del régimen culparon al Gobierno francés por la independencia de Marruecos, así como acusaron a su Gobierno provisional en Argel dirigido por Robert Lacoste de haber facilitado la infiltración comunista en África del Norte.

Pero el franquismo fue mucho más lejos a través de un artículo del periódico Ya publicado el 23 de mayo de 1956, titulado «Análisis del conflicto

${ }^{44}$ Otero, 1996, I-2. 
argelino», en el que se podía leer una dura crítica al Gobierno francés que se negaba a reconocer el derecho de Argelia a su soberanía, por lo que era responsable del fracaso de las conversaciones secretas abiertas en El Cairo con los jefes del $\mathrm{FLN}^{45}$. Con este escrito la prensa española ridiculizó a la IV República francesa pues desvelaba unas conversaciones secretas entre el gabinete de Guy Mollet y los dirigentes del FLN, todavía muy polémicas para la opinión pública francesa y que además no habían servido para nada.

Aunque lo más sorprendente era que en Madrid se supiera de estos encuentros, y es que la administración franquista estaba muy bien informada gracias a los diplomáticos españoles destacados en países árabes, nexo entre el Gobierno español y la rebelión argelina. Era el caso de José María Campoamor, cónsul en Uchda, que se reunía regularmente con el representante local del FLN. De hecho fue a través de Campoamor que llegó al gabinete de Franco una petición del Frente de Liberación para abrir una delegación en Madrid similar a la que ya existía en El Cairo; abierta poco después fue una de las primeras representaciones diplomáticas en el extranjero. Como Campoamor hubo otros muchos diplomáticos, Maestro de León en Fez o Miguel de Lojendio en Tánger, que se convirtieron en portavoces del FLN ante el Gobierno central. Lo cierto era que la mayoría de diplomáticos españoles en países árabes estaban a favor de la independencia de Argelia, por lo que tuvieron un papel importante en la política árabe de Franco ${ }^{46}$.

En la península ibérica, Madrid seguía siendo un punto de encuentro y de paso para los nacionalistas magrebíes que luchaban contra el colonialismo francés. Sin embargo esto no se debía sólo al hecho de que España apoyase la independencia argelina, sino también por la situación geoestratégica de la península ibérica, lugar de tránsito obligado entre Francia y el Magreb al ser Madrid una escala aérea habitual en los vuelos entre El Cairo y Rabat, Argel o Túnez. Por ende el Quai d'Orsay concluyó que:

«España siempre había sido un lugar de paso muy frecuentado por los jefes de la rebelión y sus agentes, y que la organización FLN estaba bien amparada en la península ibérica, ya fuese para sus pasajeros clandestinos o para el tráfico de armas.» ${ }^{47}$

45 AMAE, G. De la Tournelle, ambassadeur de France en Espagne à son excellence M. le Min des AE, 28 de junio de 1956, Serie Europa, subserie España 1956-1960, EU-14-23-16.

${ }^{46}$ Por ejemplo: AGA, El cónsul de España en Tetuán, Santiago Sangro, a Castiella, fondo AA.EE (10), Caja 82/12918.

47 (traducido del francés) Otero, 1996, I-2. 
Era innegable que las armas españolas estaban por todas partes en Argelia debido a que además de las que el general Valiño y sus agentes proporcionaban directamente al $\mathrm{FLN}^{48}$, estaban las que les llegaban indirectamente a través de otros Estados (Egipto, Marruecos y Túnez) que compraban armas a España ${ }^{49}$. Pero a pesar de la existencia de estos circuitos las necesidades en armamento eran cada vez mayores y a partir del verano de 1955 Boudiaf buscó nuevos enlaces para que llegasen más armas.

Así fue cómo Mohamed Boudiaf encontró un traficante de armas llamado Georg Puchert. Este antiguo oficial de la Kriegsmarine no había digerido la derrota del III Reich contra Francia por lo que aceptó rápidamente aliarse a la causa argelina. Se comprometió a proporcionar armas a los soldados argelinos y para ello aumentó su flota comprando nuevos barcos. Puchert entregó su primer arsenal, un cargamento de 1.000 pistolas ametralladoras al FLN en septiembre de 1955. A principios del año 1956 el contrabandista se instaló en Madrid donde adquirió material militar (tiendas de campaña, uniformes, botas, equipos de transmisión...) que también envió a Argelia. Luego se trasladó a la RFA desde donde continuó enviando armas a Argelia durante el año 1956. Naturalmente Puchert contaba con varios contactos en España para realizar sus viajes y envíos ${ }^{50}$.

Su principal socio en la península ibérica era M'hamed Yousfi, alias Si Mustapha, jefe de la delegación del FLN en Madrid (todavía no oficial), miembro de la ALN y responsable del armamento y la logística en el Ministère de l'Armement et des Liaisons Générales, el servicio secreto argelino oficialmente creado en septiembre de 1957. Su presencia en la capital española respondía a las nuevas exigencias militares de la Wilaya $V$ a la que estaba asignado. Larbi Ben M'hidi, comandante de la Wilaya V, quería abastecer a sus soldados de forma más organizada y regular en parte a través de España y para ello envío a M'hamed Yousfi a la península ibérica durante la primavera de 1956.

Si Mustapha encontró alojamiento en Madrid gracias a un buen amigo suyo, el doctor Hafid Ibrahim, tunecino asentado en la capital española desde 1945. El doctor Ibrahim ya había ayudado a los nacionalistas

48 González Mata, 1977, p. 21.

49 Al Dib, 1985, pp. 114-116.

50 Entrevista a David Paniego, yerno de Georg Puchert (Madrid, 4 o 5 de septiembre de 2014). 
marroquíes a raíz de la destitución del sultán Mohamed V en 1953 al haber organizado desde Madrid la compra y envío de armas a la ALM ${ }^{51}$. Hafid Ibrahim instaló a Yousfi en una pensión situada en la calle Saínz de Baranda n. 19 en el barrio del Retiro y para justificar su estancia en Madrid M'hamed Yousfi se hizo pasar por un estudiante universitario de castellano e Historia Universal. En la universidad encontró apoyos a la causa argelina entre los cuales había varios jóvenes latinoamericanos que reforzaron el núcleo simpatizante del FLN. Al mismo se unieron también los magrebíes Mohamed Delero, Baraka Abdelghani y Driss Bendjelloul quiénes según Si Mustapha «resultaron ser agentes tan ejemplares en sus peligrosas misiones por la causa de la revolución como sus hermanos argelinos en el frente. ${ }^{52}$

Otros marroquíes se unieron a la causa argelina, Si Ahmed Deghmouni, el tangerino Si Chaouni y los rifeños Si Abdelkader Ben Mimoun y Khatir Mohamed se presentaron voluntarios para asistir a la ALN en el suministro de armas desde España. Por su lado varios españoles, en particular Paco y Martí (alias), estructuraron en Barcelona un servicio de compraventa de armas y municiones del que se proveía Boudiaf, quién a través de Ben Mimoun enviaba material militar al norte de Marruecos escondido en barriles de pintura ${ }^{53}$. Este puesto en Barcelona extendía sin pausa sus canales de transporte, ya fuese por tierra o por mar para poner a la Wilaya $\mathrm{V}$ al mismo nivel de ataque que las otras wilayas de Argelia. Tras la entrega de armas del barco «Dina», ya mencionada en el apartado anterior, hubo otro envío durante el otoño de 1956 transportado en el navío «Athos II». El buque escondía 70 toneladas de armamento que fueron incautadas por la marina francesa el 16 de octubre de 1956 antes de llegar a Nador ${ }^{54}$.

A sabiendas de que era imposible conseguir una imparcialidad de Marruecos y Túnez en el conflicto argelino, el Gobierno francés quería obtener al menos una neutralidad española en la Guerra de Argelia. El Secretario de Estado de Asuntos Exteriores francés, Maurice Faure se sorprendía de que España apoyase al FLN ya que según él esta posición la aislaba en la escena internacional colocándola en la misma órbita que Egipto. Ciertamente el presidente de Egipto Nasser mantenía buenas re-

\footnotetext{
51 Lebjaoui, 1970, p. 126.

52 (traducido del francés), Yousfi, 2009, p. 64.

53 Lebjaoui, 1970, p. 133.

54 Al Dib, 1985, pp. 180-181.
} 
laciones con Franco, y desde el principio de la Guerra de Argelia había elegido como agregado militar en la embajada egipcia de Madrid a Abdelmoumen Naggar para que se pusiese a disposición de los independentistas argelinos ${ }^{55}$.

Para frenar la ayuda franquista a los muyahidines Maurice Faure elaboró una estrategia que envió al embajador francés en Madrid en mayo de 1956. En la misma le indicaba los pasos a seguir para iniciar una negociación con el Gobierno español:

«Podrá señalar que, al mismo tiempo que seguimos queriendo organizar una cooperación seria entre los dos países en las cuestiones marroquíes, un deterioro en nuestros intercambios sería únicamente responsabilidad del Gobierno español si éste decidiese comprometerse en la vía que parece haber considerado. No les pedimos que nos apoyen en el asunto argelino, tan sólo consideramos que estarían muy equivocados al atacarnos en un terreno en el que justamente todos nuestros aliados occidentales, conscientes de la importancia política de esta cuestión, manifiestan cada vez más el deseo de ayudarnos. Cualesquiera que sean los resentimientos de España, sus dirigentes deberían ver que una cierta política proárabe por su parte desembocaría rápidamente en la pérdida de las últimas posesiones españolas de ultramar.. ${ }^{56}$

Esta directiva merece varios comentarios. El tono era poco hábil dado que situaba a Francia en una posición muy superior a España, y era precisamente eso lo que más irritaba al franquismo en sus relaciones diplomáticas con la República francesa. Por otra parte no todos los países occidentales apoyaban a Francia en la contienda argelina como afirmaba Faure, muchos la criticaban. Sin embargo Maurice Faure sí acierta cuando aludía a los resentimientos de España, ya que algunas acciones anti francesas no eran necesarias e iban en contra de los intereses inmediatos de España. Es decir que en algunas decisiones de responsables franquistas los sentimientos se imponían a la razón. Además Franco deseaba proseguir su integración internacional con la entrada de España en la OTAN y a posteriori en la CEE, ingresos imposibles sin el apoyo de Francia.

\footnotetext{
55 Lebjaoui, 1970, p. 129.

56 (traducido del francés) Otero, 1996, I-3.
} 


\section{Madrid - Tetuán - Rabat - Mallorca - Argel}

Franco era consciente de que su afrenta contra Francia no podía durar eternamente y que su política proárabe empezaba a perjudicar a España ${ }^{57}$. El primer aviso llegó poco después de la independencia de Marruecos cuando el dirigente del Istiqlal Allal El Fassi, cercano a España hasta el momento, pronunció un discurso en Tánger el 18 de junio de 1956 en el que exponía su concepción del «Gran Marruecos»:

«Los nacionalistas marroquíes seguirán luchando hasta que se independicen todos los territorios del Imperio Jerifiano, Tánger incluida, hasta que se liberen el Sahara bajo influencia española, el Sahara bajo influencia francesa y hasta que sean integradas en Marruecos las zonas que el colonialismo le ha arrancado, de Tinduf hasta Béchar, Touat, Kenadsa y Mauritania. Marruecos estará limitado al sur por Saint-Louis du Sénégal.» ${ }^{58}$

A partir de aquellas declaraciones, los miembros del Istiqlal y de la ALM se negaron a hacer distinciones entre la presencia española y la presencia francesa en África, ambas designadas como coloniales e ilegítimas. Es más, esta agitación nacionalista comenzó a propagarse en el enclave español de Ifni.

Estos hechos iniciaron una aproximación del Gobierno español a Francia, y a partir del verano de 1956 el gabinete franquista solicitó reunirse con autoridades francesas para hablar de la cuestión marroquí. Para el Presidente del Consejo de Ministros, Guy Mollet ésta era una gran noticia ya que responsables del Quai d'Orsay deseaban entrevistarse con diplomáticos franquistas desde los ataques en Marruecos y Argelia de octubre de 1955. Los primeros contactos bilaterales sobre Marruecos comenzaron en julio de 1956 y siguieron dos vías paralelas, una diplomática a través del embajador francés en Madrid y otra militar.

La administración Mollet estableció como única condición previa para el comienzo de estas conversaciones la neutralidad de España en Argelia donde la guerra se envenenaba cada vez más.

Consecuentemente la presión sobre el Gobierno de Guy Mollet era asfixiante ya que debía restaurar el orden en Argelia fuera como fuera. A

57 Franco Salgado-Araújo, 1976, p. 158.

58 (traducido del francés) Otero, 1996, I-3. 
tenor de ello el embajador francés en España De la Tournelle intentaba obtener garantías del Ministerio de Asuntos Exteriores sobre la posición española ante la ONU con respecto al FLN. El jefe de la diplomacia española Martín Artajo le aseguraba al embajador que España no tenía nada que ver con el FLN al mismo tiempo que se mantenía prudente en lo que atañía al voto español en las Naciones Unidas. En cualquier caso el 26 de agosto de 1956 Martín Artajo se reunió en París con su homólogo Christian Pineau para analizar la situación en Suez y en el Magreb. Tras el encuentro Artajo declaró que:

«La comprensión que pueda haber entre Francia y España no está dirigida contra nadie sino a favor del beneficio común de las tres partes interesadas, de Marruecos, Francia y España.» ${ }^{59}$

Esto significaba que la diplomacia española todavía era reacia a olvidar su política proárabe. El Gobierno franquista deseaba acercarse a Francia pero sin perjudicar su diálogo privilegiado con el Islam, de ahí que Martín Artajo buscara justificarse ante la monarquía jerifiana. Siguiendo esta línea el Gobierno franquista intentó defender un consenso en la crisis de Suez que no vulnerase la soberanía de Egipto $^{60}$.

Al fin y al cabo la política árabe había acaparado la política exterior franquista desde el principio del régimen aportándole buenos resultados.

Si bien los avances entre diplomáticos franceses y españoles eran tímidos, en el plano militar la colaboración franco-española sí que dio resultados rápidamente, pues permitió una acción local y directa sobre el terreno. El 7 de julio de 1956 hubo una primera reunión entre mandos militares españoles y franceses en el Quai d'Orsay. El motivo del encuentro era examinar el futuro estatuto del ejército marroquí así como el de las tropas francesas y españolas estacionadas en Marruecos. Durante las conversaciones el Coronel Maldonado Vázquez cercano al almirante Luis Carrero Blanco trató de conocer la postura francesa ante posibles revueltas en las posesiones españolas. Los militares franceses le respondieron que en dicho caso apoyarían a España aunque de momento esa posición era oficiosa.

Como el balance de los intercambios militares era positivo, Alberto Martín Artajo quiso aprovecharlo el 6 de noviembre de 1956 y pro-

\footnotetext{
59 (traducido del francés) Otero, 1996, I-3.

60 Gavín, 2017.
} 
puso a De la Tournelle una reunión con el objetivo de estudiar «un proyecto de acuerdo para reprimir el contrabando de armas en el conjunto de Marruecos.» ${ }^{61} \mathrm{El}$ embajador le contestó que la redacción de un texto oficial sería inoportuna en la medida en la que Francia quería evitar que el Gobierno jerifiano supiese de la colaboración militar franco-española. Por último añadió que era mejor que se encargasen de este asunto las autoridades militares de Madrid y de París.

Las razones que dio la diplomacia francesa para oponerse a una colaboración oficial eran legítimas pero existían otros motivos para no rubricar un documento oficial bilateral. El Gobierno francés no quería implicarse con España en Marruecos, dado que tan sólo le pedía neutralidad en el Magreb. Las pasadas experiencias franco-españolas en el norte de África no habían salido bien y las autoridades francesas consideraban el problema argelino como un problema franco-francés en el que no debía inmiscuirse ninguna otra nación. El aceptar la colaboración de España de forma oficial hubiera dado pie a Estados Unidos y por consiguiente a la OTAN a entrometerse en la cuestión de la defensa en África del Norte. A esto se añadía el hecho de que España era una dictadura con la que la IV República francesa, cuya imagen internacional ya era francamente negativa, no quería mezclarse demasiado por la mala prensa que ello traería.

Al franquismo, en constante búsqueda de reconocimiento internacional, no le satisfacía del todo esta respuesta pero sus jefes eran muy conscientes de que iban a necesitar la ayuda francesa en Ifni y el Río de Oro si se confirmaba el auge nacionalista.

Durante las siguientes semanas, hubo más contactos bilaterales a través de agregados militares de ambas embajadas o directamente entre militares a nivel local para intercambiar información sobre los movimientos de la ALM, de los líderes nacionalistas así como del tráfico de armas en las regiones meridionales de Marruecos colindantes con Mauritania.

Poco a poco franceses y españoles comenzaron a ver en los nacionalistas magrebíes un enemigo común, lo cual acercaba sus posiciones en el norte de África.

Asimismo es interesante señalar que aún habiendo recuperado el Imperio Jerifiano su libertad, éste continuaba siendo esencial en las relaciones franco-españolas.

61 Otero, 1996, I-3. 
En aras de este interés mutuo, el general Agustín Muñoz Grandes, Ministro del Ejército entre 1951 y 1957, buscaba llegar a acuerdos con mandos militares franceses en Marruecos. Su cercanía al caudillo no pasó desapercibida para Guy le Roy de La Tournelle que en mayo de 1956 escribió:

«El Gobierno español tiene por costumbre estar muy indeciso sobre la política a adoptar al mismo tiempo que está asustado por la situación en Marruecos y presionado por algunos ministros, entre los cuales está el general Muñoz Grandes, resignado a buscar una colaboración con nosotros.» ${ }^{62}$

La palabra «colaboración» quizás sea demasiado fuerte para describir la relación bilateral de la segunda mitad de 1956. No obstante sí que se puede hablar de cooperación como por ejemplo el aviso que en septiembre de 1956 dieron las autoridades españolas al ejército francés con respecto a un barco en el puerto de Cádiz sospechoso de estar cargado de armas con destino a África del Norte ${ }^{63}$.

En cualquier caso lo que encauzó el acercamiento bilateral fue la postura de España ante uno de los episodios históricos más importantes de la Guerra de Argelia como fue el secuestro del avión que transportaba a los líderes del FLN.

Todo comenzó el 16 de octubre de 1956 cuando los jefes del FLN Mohamed Khider y Aït Ahmed llegaron a Madrid para luego ir a Marruecos dónde querían explicarle a Mohamed V la posición que tendría el FLN en una importante conferencia magrebí organizada por el Primer Ministro de Túnez Habib Bourguiba en la capital homónima.

Ben Bella se unió a ellos en Madrid y, el 20 de octubre de 1956, Ben Bella, Khider, el doctor Hafid Ibrahim y el espía M'hamed Yousfi despegaron de Barajas rumbo a Tetuán.

Diez minutos después de despegar de Madrid uno de los motores del Douglas se incendió. «Un calor sofocante invadió la cabina asfixiando a los pasajeros» ${ }^{64}$.

Cuando vio las llamas la azafata entró en pánico un instante antes de alertar al comandante de la aeronave que apagó el motor para así evitar males mayores. Seguidamente éste dio la alerta a la torre de control que

\footnotetext{
62 (traducido del francés) Otero, 1996, I-3.

63 AMAE (1956-1960), serie Europa, subserie España, Eu - 14 - 23 - 16.

64 (traducido del francés) Yousfi, 2009, p. 81.
} 
le permitió volver al aeropuerto de Barajas donde consiguió aterrizar con un solo motor y, enseguida se formó un cordón de seguridad alrededor del aparato. Los primeros indicios de la investigación policial mostraron que había sido un atentado perpetrado por el servicio secreto francés que quería evitar a toda costa que el FLN estuviese representado en la cumbre de Túnez. Enseguida después de este intento de atentado del SDECE (Servicio de Documentación Exterior y Contraespionaje), Ben Bella y los demás tomaron otro Douglas DC3 que sin más contratiempos llegó a Tetuán donde les esperaba el príncipe Hassan.

Desde Tetuán se trasladaron a Rabat, donde se entrevistaron con el sultán Mohamed V para resumirle el que sería su discurso durante la Conferencia Magrebí de Túnez: continuación de la lucha armada del pueblo argelino, en el marco de la solidaridad magrebí, hasta su independencia.

Al día siguiente la delegación del FLN tomó un avión para ir hacia Túnez con una escala prevista en las Islas Baleares. Ciertamente el SDECE estaba al corriente de todos los detalles de este vuelo e informaba directamente a varios mandatarios franceses en Argelia entre los cuales se encontraban Michel Gorlin, Director del Gabinete Civil y el teniente coronel Branet. Ambos decidieron desviar el avión del FLN hacia Argelia y una vez interceptado por el ejército del aire francés, el piloto fue obligado a aterrizar en Argel. En tierra los pasajeros del vuelo, la plana mayor del Frente de Liberación Nacional, fueron detenidos y encarcelados por la policía francesa.

Naturalmente esto dio al traste con las negociaciones secretas, ya extremadamente complicadas de por sí, entre el gabinete Mollet y el FLN. Por otra parte las relaciones entre Francia y sus antiguos protectorados, Marruecos y Túnez, se suspendieron ya que tanto Mohamed V como Bourguiba no digirieron esta intromisión francesa en asuntos magrebíes y trajeron de vuelta a sus embajadores de París. Asimismo tras el arresto de los jefes del FLN hubo graves disturbios en Marruecos que provocaron 60 muertos aproximadamente, todos europeos. Además la encarcelación de Ben Bella, Boudiaf y los demás no detuvo a los combatientes argelinos más decididos que nunca a conquistar su libertad. Boudiaf fue reemplazado por Abdelhafid Boussouf que se convirtió en el nuevo responsable del FLN en Marruecos y que enseguida tomó contacto con el doctor Khatib y el doctor Hafid Ibrahim establecido en Madrid ${ }^{65}$.

65 Lebjaoui, 1970, pp. 137-138. 
¿Pero qué postura tuvo el Gobierno español ante el secuestro del avión por parte de las autoridades francesas?

El cónsul español en Fez, Maestro de León, afirmó que durante las manifestaciones por el arresto de los líderes argelinos los marroquíes al ver su coche gritaban $\ll_{i}$ Viva España!» y $« i$ Viva Franco! ${ }^{66}$. Aunque esto fuera cierto el Gobierno franquista no se quejó ante las autoridades francesas por el secuestro del avión, aún habiéndose producido en el espacio aéreo español, argumento importante en incidentes internacionales de este tipo $^{67}$. Tampoco dijo nada ningún responsable franquista con respecto al intento de atentado en el vuelo de los líderes argelinos que salía de Barajas hacia Tetuán. Peor aún, numerosas personalidades españolas felicitaron a Francia por la captura de los jefes del FLN ${ }^{68}$. Como es lógico estos hechos provocaron una pérdida de confianza de las naciones árabes hacia España, las cuales hubieran esperado algún tipo de protesta por parte del franquismo, su aliado histórico.

\section{Conclusión}

Este artículo demuestra que hubo un apoyo del franquismo a la revolución argelina a través de diferentes canales.

En primer lugar a través de la prensa franquista que criticaba muy duramente el colonialismo francés al mismo tiempo que apoyaba la independencia de Argelia. Al ser una dictadura el mensaje de la prensa española era único por lo que su eco resonaba con fuerza en la escena internacional. Tanto era así que en los archivos del Ministerio de Asuntos Exteriores francés se pueden encontrar un sinfín de comentarios sobre los artículos españoles concernientes a Argelia.

En segundo lugar los franquistas proporcionaron una ayuda logística fundamental a la revolución argelina que si bien es cierto que al final de la guerra tuvo muchos apoyos internacionales careció de ellos al principio. El ejército y el servicio secreto español, el Segunda Bis, eran grandes conocedores de la cultura y costumbres norteafricanas lo que facilitó su infiltración y ayuda a los muyahidines magrebíes.

66 Otero, 1996, I-3.

67 Ybarra Enríquez de la Orden, 1998, pp. 310-311.

68 (1956-1960) AMAE, serie Europa, subserie España, Eu - 14 - 23 - 16. 
Por otra parte la política árabe de Franco y más concretamente el apoyo español a la revolución argelina cumplió sus objetivos al mantener la presión sobre Francia por su amparo a los republicanos españoles y conseguir mayor legitimidad para el régimen en la escena internacional. La dictadura española asimiló su política árabe a una política anticolonial bien recibida por las Naciones Unidas y por los Estados Unidos cada vez más críticos con el imperialismo de la inestable IV República francesa. De igual modo los franquistas consiguieron granjearse la amistad de los países árabes más presentes en la comunidad internacional gracias a la conquista de sus independencias. En lo que respecta a Argelia, España quería recuperar influencia en ese territorio clave por su cercanía histórica, geográfica, cultural, demográfica y económica acaparado desde el siglo XIX por Francia. Así pues, España intentó conservar un papel central y determinante en el Mediterráneo mediante la política argelina.

Sin embargo la política árabe de Franco comenzó a virar a finales del año 1956. El apoyo franquista a una Argelia independiente había sido casi incondicional desde el principio de la guerra pero esta ayuda estaba empezando a perjudicar los intereses españoles en África del Norte dado que sus últimas posesiones coloniales estaban ansiosas por seguir a sus hermanos norteafricanos emancipados. Varios altos mandos del régimen, entre los cuales estaba el general Muñoz Grandes, deseaban acercarse más a Francia y a Europa en detrimento de los países árabes ya que por muchas críticas que recibiera Francia, ésta seguía siendo un referente y una potencia en la escena internacional, muy por encima de la España franquista. El país vecino, miembro y fundador de las organizaciones internacionales del momento era indispensable para proseguir la integración occidental del franquismo.

Esto suponía distanciarse de África y del mundo árabe tan apreciados por los africanistas. El norte de África estaba en el ADN del franquismo con lo que un cambio en la política exterior iba a ser complicado y lento. Entre los defensores del africanismo estaba por supuesto el general Rafael García Valiño pero también el almirante Luis Carrero Blanco, Subsecretario de la Presidencia del Gobierno y hombre de confianza de Franco. Francisco Franco era ante todo un africanista pero sabía que la política árabe tenía límites y que su Gobierno no podía seguir dando la espalda a Francia y por ende al resto de Europa por mucho más tiempo. Estas dos tendencias dieron lugar a disensiones en el seno del gabinete franquista a partir de 1957. De igual manera se hizo patente el 
discurso contradictorio de España, que al mismo tiempo que defendía la independencia de los países árabes, no quería conceder la libertad ni al Sahara ni a Ifni.

Consecuentemente en 1957 se materializó un cambio de política exterior que marcó el fin del apoyo franquista a la independencia argelina y el inicio de una etapa más pro europea.

El gobierno franquista cambiaba así su chaqueta para una vez más adaptarse a la nueva situación internacional. Lo cierto era que la diplomacia camaleónica de la España franquista no tenía una estrategia predeterminada, sino que iba siguiendo las tendencias internacionales a medida que iban surgiendo, eso sí, dentro de sus posibilidades. Por muy ladino que fuese, Francisco Franco no consiguió engañar a la comunidad internacional, que siempre condenó su régimen. Además el franquismo nunca abandonó del todo la política pro árabe.

Por último es fundamental señalar que el FLN tomó verdadero protagonismo a partir del año 1956 ya que salió de la sombra en la que le mantenía Francia. Irrumpió de forma brutal en la historia con la Toussaint rouge, pero durante dos años sólo se les conoció a través de medios de comunicación occidentales, principalmente franceses, que les representaban como una banda terrorista minoritaria y sin norte.

El año 1956 fue clave para la lucha argelina pues fue el año en el que se independizaron sus dos vecinos magrebíes, Marruecos y Túnez. Este acontecimiento legitimó y reforzó al nacionalismo argelino que ganó presencia en la escena internacional gracias al Bloque de Bandung y a sus acciones en la ONU. Gracias a este paso el FLN empezó a ser considerado como una organización político-militar más que como una banda terrorista. Tanto fue así que Argelia emerge con voz propia, ya no a través del Imperio Otomano ni del Imperio Español ni del Imperio Francés. El enfrentamiento franco-español deja de acaparar toda la acción y Argelia comienza a existir por sí misma. A partir de ahí sus voces jamás volvieron a silenciarse.

\section{Fuentes}

- Archives du Ministère des Affaires Étrangères de France (AMAE)

- Archivo Central del Ministerio de la Presidencia (ACMP), Serie Jefatura de Estado (J.E.)

- Foreign Relations of the United States (FRUS) 
- Service Historique de la Défense de France (SHD), Service Historique de l'Armée de Terre (SHAT)

- Archivo General de la Administración (AGA), fondo Asuntos Exteriores (AA.EE)

- Entrevista a David Paniego, yerno de Georg Puchert (Madrid, 4 o 5 de septiembre de 2014).

\section{Bibliografía}

AL DiB, Fatih, Abdel Nasser et la révolution algérienne, L'Harmattan, Paris, 1985.

Algora Weber, María Dolores, «Argelia en la política exterior del régimen de Franco: Continuidad o ruptura en la tradicional amistad hispano-árabe», en Pereira Castañares, Juan Carlos (dir.), Del aislamiento a la apertura: la política exterior de España durante el franquismo, Comisión Española de Historia de las Relaciones Internacionales, Madrid, 2006.

ALONSO CASTRILLO, Álvaro, «Les rapports franco-espagnols au Maroc (1953-1956): Étude des presses madrilène et parisienne », [Trabajo de fin de Máster], Institut d’Études Politiques, Paris, 1958.

BALFour, Sebastian y LA PORTE, Pablo, «Spanish military cultures and the Moroccan wars 1909-36», European History Quarterly, 30, 3, 2000, pp. 307-332.

Bautista Vilar, Juan, España en Argelia, Túnez, Ifni y Sahara, IEA - CSIC, Madrid, 1970.

BAUTISTA VILAR, Juan, Emigración española a Argelia (1830-1900). Colonización hispánica de la Argelia francesa, Instituto de Estudios Africanos (IEA) - CSIC, Madrid, 1975.

BenbelaïD, Amar, C'était Boudiaf: Essai historique, Société des Ecrivains, Paris, 2007.

BRAnche, Raphaëlle, La Guerre d'Algérie : une histoire apaisée ?, Seuil, Paris, 2005.

Connelly, Matthew, A diplomatic revolution: Algeria's fight for independence and the origins of the post-cold war era, Oxford University Press, New York, 2002.

Delaunay, Jean-Marc, Méfiance cordiale. Les relations franco-espagnoles de la fin du XIXème siècle à la Première Guerre Mondiale. Volume 2: Les relations coloniales, L'harmattan, Paris, 2010.

Delgado GómEZ-EsCALONILLA, Lorenzo, «El "amigo americano"? España y Estados Unidos durante el franquismo», Studia Historica. Historia Contemporánea, 21, 2003, pp. 231-276.

DuLPHY, Anne, La politique de la France à l'égard de l'Espagne de 1945 à 1955. Entre idéologie et réalisme, Ministère des Affaires Étrangères, collection diplomatie et histoire, Paris, 2002. 
DulPhy, Anne, «La guerra de Argelia y sus repercusiones en España» en Eloy Martín Corrales y Josep Pich Mitjana (eds.), La guerra de independencia de Argelia y sus repercusiones en España, Bellaterra, Barcelona, 2018.

Franco Salgado-Araúso, Francisco, Mis conversaciones privadas con Franco, GeoPlaneta, Barcelona, 1976.

Gavín, Víctor, «España y la crisis de Suez. Una breve ilusión hace 60 años (1956)», Miscelánea de estudios árabes y hebraicos, 66, 2017, pp. 77-96.

GonzÁlez Mata, Luis Manuel, Cisne. Espía de Franco, Argos, Barcelona, 1977. GuENTARI, Mohamed, Organisation politico-administrative et militaire de la révolution algérienne de 1954 à 1962, Office des Publications Universitaires, Alger, 2002.

Hernando de Larramendi, Miguel, «España ante la independencia de Marruecos», en Martin Corrales, Eloy y Pich Mitjana, Josep (eds.), España frente a la independencia de Marruecos, Bellaterra, Barcelona, 2017, pp. 163-190.

IGLESIAS AMORÍN, Alfonso, «La cultura africanista en el ejército español (19091975)», Pasado y Memoria. Revista de Historia Contemporánea, 15, 2016, pp. 99-122.

LATROCH, Djamel, «La sociedad argelina vista por viajeros españoles (18451895): estructura social y poblacional» en TERKI HASSAINE, Ismet, Sola Castaño, Emilio, R. Díez Torre, Alejandro y Casado Arboniés, Manuel (eds.), Las campanas de Orán, 1509-2009. Estudios en homenaje a Fatma Benhamamouche, Universidad de Alcalá, Alcalá de Henares, 2012.

Lebjaoui, Mohamed, Vérités sur la révolution algérienne, Gallimard, Paris, 1970.

LleONART Amsélem, Alberto José, «El ingreso de España en la ONU: obstáculos e impulsos », Cuadernos de historia contemporánea, 17, 1995, pp. 101-119.

López García, Bernabé y Hernando de Larramend, Miguel, España, el Mediterráneo y el mundo arabomusulmán, Icaria, Barcelona, 2010.

Malgat, Gérard, «Voix de la France, voix de l'exil. Les émissions en langue espagnole de la radiodiffusion française entre 1945 et 1968 », [Trabajo de fin de Máster], Université de Paris X-Nanterre, Paris, 1997, [Consultado el 27/09/2019] (disponible en: https://devuelvemelavoz.ua.es/es/documentos/ pdf/voix-de-la-france.pdf)

Michal, Bernard, Histoire du drame algérien 1954-1962, Omnibus, 2012, [Consultado el 27/09/2019] (disponible en: https://books.google.fr/ books?id=FyHZ09L--awC\&printsec $=$ frontcover \&dq=Bernard+Michal+Hi stoire+du+drame+alg\%C3\%A9rien\&hl=es\&sa=X\&ved=0ahUKEwiuzqfy qIjbAhWDaVAKHY5TAogQ6AEIJzAA\#v=onepage \&q=Bernard\%20Michal\%20Histoire \%20du\%20drame\%20alg\%C3\%A9rien\&f=false)

Morales LezCANO, Víctor, Africanismo y orientalismo español durante el siglo XIX, UNED, Madrid, 1989. 
NeIla HeRnándeZ, José Luis, España y el Mediterráneo en el siglo XX. De los acuerdos de Cartagena al proceso de Barcelona, Sílex, Madrid, 2011.

OTERO, Maruja, « L'Algérie dans les relations franco-espagnoles 1954-1964 », [Trabajo de fin de Máster], Institut d'Études Politiques, Paris, 1996.

PANIAGUA LóPEZ, Julián, «La red de servicios secretos españoles durante la Guerra del Rif (1921-1927): Los servicios especiales reservados dirigidos por Ricardo Ruiz Orsatti», Revista de Historia Contemporánea de la Universidad del País Vasco, 57, 2018, pp. 491-512.

Pereira Castañares, Juan Carlos (dir.), Del aislamiento a la apertura: la política exterior de España durante el franquismo / III Jornadas de la Comisión Española de Historia de las Relaciones Internacionales, Universidad de Burgos, octubre 2004, Comisión Española de Historia de las Relaciones Internacionales, Madrid, 2006.

Pervillé, Guy, Guerre d'Algérie. Histoire et Mémoires, CRDP d'Aquitaine, Bordeaux, 2008.

De Rochebrune, Renaud y Stora, Benjamin, La Guerre d'Algérie vue par les algériens. Des origines à la Bataille d'Alger, Denoël, Paris, 2011.

SANTAMARÍA, Ramiro, Ifni-Sahara. La guerra ignorada, Dyrsa, Madrid, 1984.

TERKI HASSAINE, Ismet, Relaciones políticas y comerciales entre España y la Argelia otomana (1700-1830), Universidad de Alcalá, Alcalá de Henares, 2011.

ThÉNAult, Sylvie, Algérie, des événements à la guerre : idées reçues sur la guerre d'indépendance algérienne, Le Cavalier Bleu, Paris, 2012.

TORRes García, Ana, «El gobierno de España y la Organización del Ejército Secreto (OAS), 1960-1962», en Martin Corrales, Eloy y Pich MituanA, Josep (eds.), España frente a la independencia de Marruecos, Bellaterra, Barcelona, 2018, pp. 99-124.

Villanova, José Luis, El protectorado de España en Marruecos. Organización política y territorial, Bellaterra, Barcelona, 2004.

WaLl, Irwin, Les Etats-Unis et la Guerre d'Algérie, Soleb, Paris, 2006.

Ximénez de Sandoval, Crispín y Madera Vivero, Antonio, Memorias sobre la Argelia, Rivadeneyra, Madrid, 1853.

YBARRA EnRíQuez DE la ORden, María Concepción, España y la descolonización del Magreb. Rivalidad hispano-francesa en Marruecos (1951-1961), UNED, Madrid, 1998.

Yousfi, M'hamed, L'Algérie en marche. Tome II, ENAG, Alger, 2009.

Zavala, Francisco, La bandera española en Argelia. Anales históricos de la dominación española en Argelia desde 1500 a 1791, Gojoso y Compañía, Argel, 1885. 


\section{Datos del autor}

Manuel Vidal Muñoz es historiador. Graduado en Historia por la Universidad Autónoma de Madrid, realizó un Máster en Historia y Civilizaciones Comparadas en la Université Paris VII - Denis Diderot. Su TFM, "L'Espagne et la Guerre d'Algérie», ha sido publicado por la Unidad de Investigación sobre Seguridad y Cooperación Internacional de la Universidad Complutense de Madrid: http:// www.unisci.es/lespagne-et-la-guerre-dalgerie/. Doctor en Historia Contemporánea por la Universidad Autónoma de Madrid, hizo una estancia de investigación en l'Ecole Polytechnique de Paris durante la cual redactó un artículo de investigación, "L'Espagne et la conquête de l'Algérie (1830-1847)", pendiente de aprobación en la Revue d'histoire du XIXe siècle. Sus investigaciones se centran en la relación entre España y Argelia durante la época contemporánea y por ende en el rol de la península ibérica en el Mar Mediterráneo. 